\title{
Effect of age on pressure-flow dynamics in secundum atrial septal defect
}

\author{
HYMIE S JOFFE
}

\author{
From the Cardiology Department, Bristol Royal Hospital for Sick Children and Bristol Royal Infurmary, Bristol, \\ Avon
}

The first descriptions of the haemodynamic events in isolated atrial septal defect date back to the $1940 \mathrm{~s}^{1-9}$ yet a complete understanding of the precise flow patterns across the defect remains elusive. This is partly because of the complex and varying pressure and volume characteristics of the atria themselves, even with an intact septum, and partly because attempts to time and quantify the components of the interatrial shunt with available techniques of investigation have produced conflicting results.

Two papers in this issue draw attention once more to the vagaries of this subject. ${ }^{1011}$ Both indicate inter alia that haemodynamic patterns change with age or duration of left to right shunting, and appreciation of this fact may help explain the disparate interpretations of the variable interatrial pressure-flow dynamics in atrial septal defect. Galve et al confirm that a right to left shunt occurs in an appreciable number of patients (15\%), 10 an observation first described as "cyanose tardive" by Bard and Curtillet in 1889,12 and subsequently demonstrated by peripheral ${ }^{13}$ or central 467914-16 oximetry, angiocardiography, ${ }^{17} 18$ or by dye dilution, 1517 fibreoptic catheter, ${ }^{19}$ or echocardiographic ${ }^{20}$ and intracardiac Doppler ${ }^{21}$ techniques. The reported incidence of right to left shunting varies from $14 \%^{22}$ to $100 \% .{ }^{17}$ Galve et al show that this phenomenon is not associated with increased right atrial, right ventricular, or pulmonary artery pressures. 10 Although a right to left shunt has been found in cases of atrial septal defect in infancy 9 and childhood, ${ }^{23}$ Gault et al ${ }^{24}$ and Dexter, ${ }^{16}$ in the $1955 \mathrm{St}$ Cyres lecture, also emphasise that this event occurs predominantly in older patients.

Parikh et al ${ }^{11}$ have approached the haemodynamic conundrum from the viewpoint of atrial pressure wave morphology and show that the alteration of the normal right atrial wave form (" $a$ " $>$ " $v$ " wave) to a pattern of a dominant "v" wave ("v" $>$ "a"), so called

Requests for reprints to: Dr H S Joffe, Peediatric Cardiologist, Bristol Royal Hospital for Sick Children, St Michsel's Hill, Bristol, Avon BS2 8BJ. "left atrialisation" of the right atrial wave form, previously described as a feature of large atrial septal defects, becomes less frequent with increasing age. Furthermore, "right atrialisation" ("a" $>$ " $v$ ") of the normal left atrial wave form (" $v$ " $>$ " $a$ ")-which is less important clinically since it is not evident in the jugular venous pulse but is unexpected and intriguing haemodynamically-occurs more frequently in older patients. Do these alterations of the phasic wave form and the occurrence of right to left shunting, both of which are age dependent and apparently unrelated to raised right atrial and right ventricular end diastolic pressures, give a clue to the circumstances promoting the right to left shunt? To evaluate this possibility knowledge of the precise timing of the right to left shunt is crucial, but previous reports have been contradictory.

Levin et al, in a seminal paper on the atrial pressure-flow dynamics in secundum atrial septal defects, ${ }^{17}$ showed that the major left to right shunt and pressure gradient occur during late ventricular systole and early diastole, coincident with the atrial "v" waves and while the atrioventricular valves are closed, with augmentation during the "a" wave of atrial contraction. Minute right to left shunts and pressure gradients were noted in all cases during very brief periods at the onset of ventricular contraction and occasionally during early ventricular diastole (at the trough of the " $y$ " descent). In none of these patients, however, was the right to left shunt detected in the systemic circulation by the indicator dilution method suggesting that the transatrial shunt was small, occurred at a phase when the mitral valve was closing, and was simply washed back into the right atrium with the ensuing " $v$ " wave. It is noteworthy that all patients in this series were young (under 14 years). Using a directional ultrasonic Doppler probe mounted at the tip of a catheter and placed at the site of the atrial septal defect, Kalmanson et al measured the instantaneous forward and reverse blood flow velocity and confirmed the timing of bidirectional shunts as above. ${ }^{21}$ (The ages were not identified in this group of 10 patients.) On the other hand, Lind and 
Wegelius, using cineangiography after an injection of a contrast medium into the inferior vena cava of children, showed that small transient right to left shunts occur during atrial diastole but that the coexistence of severe pulmonary stenosis results in a dominant right to left flow during atrial systole. ${ }^{18}$ Shaffer et al also show that reversal of the interatrial gradient synchronous with a right to left flow occurs during atrial systole in patients with pulmonary stenosis. ${ }^{14}$ Even after relief of pulmonary valve stenosis residual impairment of right ventricular distensibility may lead to a right to left shunt in association with elevated right atrial "a" waves. ${ }^{25}$ Rasmussen et al quantified the net right to left shunt by polarographic determination of systemic arterial oxygen tension during pure oxygen breathing and found that a right to left shunt occurred in $55 \%$ of their patients with isolated atrial septal defects and that the magnitude correlated best with the height of the right atrial "a" wave. 13 All patients in this study were over 15 years old. Since right atrial systole starts about $20 \mathrm{~ms}$ before that of the left, ${ }^{21326}$ the right atrial systolic force may be unopposed at this time, thus encouraging flow from right to left.

It seems likely, therefore, that different methods of detection will give widely varying frequencies of a right to left shunt; "transient" shunting into the left atrium (detected by cineangiography or Doppler techniques) occurs in most, if not all, patients of any age with large atrial septal defects whereas "sustained" shunting into the systemic circulation (demonstrated by dye dilution and oxygen tension or saturation studies) occurs less frequently, with a tendency to evolve with age, and takes place at a different phase of the cardiac cycle in association with a prominent right atrial "a" wave.

Many theories have been advanced to explain the right to left shunt apart from those instances when a vena cava connects directly with the left atrium ${ }^{27} 28$ or the right ventricle is hypoplastic. ${ }^{29}$ Early reports ascribed this phenomenon to congestive heart failure 1316 or increased pulmonary vascular resistance, 6162330 but Galve et al refer to several reports of isolated cases in which neither heart failure nor pulmonary hypertension was present. ${ }^{10} \mathrm{It}$ is of interest that even in patients with severe pulmonary vascular disease, in whom right to left shunting is more common, mean right atrial and right ventricular end diastolic pressures are not raised.16 Some authors propose that normal anatomical features favour flow from the inferior vena cava to the left atrium, 151827 but why this should happen in only some cases is not clear. The size of the defect is rarely so large 9 as to permit common mixing, 16 as in a common atrium. While decreased compliance of the right heart chambers is often incriminated as the cause of right to left shunting, 101115162731 it has been difficult to reconcile this with the finding of normal mean right atrial and right ventricular end diastolic pressures, 14791620222331 or with the equal mean pressures in the two atria in the case of large defects. 5716 Several authors claim that the direction of interatrial flow, in the face of equal filling pressures, depends on the relative distensibilities of the two ventricles, ${ }^{4711162531}$ but this does not explain why a right to left shunt is often associated with a large left to right shunt. 16

With few exceptions, 17111417 however, most authors appear to overlook two important factors. One is the role of phasic interatrial pressure gradients on flow direction; Shaffer et al showed that a presystolic right to left shunt and " $a$ " wave gradient can coexist with a left to right shunt and mean and " $v$ " wave gradients. ${ }^{14}$ The other factor that acts as a major determinant of these cyclical events is the relative compliance or distensibility of the atria as well as the ventricles during different phases of the cardiac cycle, as described lucidly and in detail by Hull as long ago as 1949.7

In normal individuals, the decreased deformability of the left atrium, considered to be due to the thicker left than right atrial wall and the smaller venous reservoir on the left, ${ }^{1-3711}$ results in higher pressures in the left atrium during maximal venous inflow (" $v$ " wave), whereas the longer, narrower, and more muscular left than right ventricle ${ }^{8}$ results in somewhat higher left atrial pressures during atrial outflow (ascending " $y$ " and " $a$ " waves). Suga showed experimentally that the effective source pressure for venticular filling was not the continuous mean atrial pressure but the mean pressure during ventricular diastole on$1 y,{ }^{32}$ and this pressure becomes raised with decreased atrial compliance. In the presence of a small atrial septal defect the higher left atrial pressures during all phases of the cardiac cycle result in almost continuous left to right flow, accentuated during the " $v$ " and " $a$ " peaks. ${ }^{17}$ When the interatrial communication is large and unrestrictive with equalisation of the mean pressures, however, the relative ventricular resistances have a major influence on the " $a$ " wave gradient at end diastole but little effect on the " $v$ " wave gradient since the atrioventricular valves are closed during maximal filling of the atria, ${ }^{71417}$ and left to right flow at this stage is facilitated by the greater distensibility of the right atrium. Since this is essentially a passive phenomenon with free run-off through a large septal defect, the relatively non-distensible left atrium remains small, as noted clinically and at necropsy, ${ }^{7}$ while the right atrium dilates to accommodate the increased volume. Thus in the face of equal filling (or mean atrial) pressures the direction of flow will be determined by relative ventricular distensibilities dur- 
ing atrial systole ("a" wave) and by relative atrial compliance during atrial diastole (" $v$ " wave).

A comprehensive explanation for the seemingly paradoxical findings at different ages is now possible. In the newborn and the infant, the persisting fetal hypertrophy of the right atrium and ventricle will tend to resist the left to right shunt during both the "a" and " $v$ " waves and probably accounts for the rare presentation at this age. ${ }^{33} 34$ Later, in the young patient, the increased pulmonary blood flow and pulmonary venous return augments the left atrial pressures, especially during the maximal filling phasethat is synchronous with the " $v$ " wave-and left to right shunting is encouraged. The mean right atrial pressure increases to match that of the left, though the left atrial "v" wave remains dominant and the left to right shunt large, and small "transient" right to left shunts may occur at the onset of ventricular systole. 171921 After a variable period of time, depending on the size of the defect and volume of the left to right shunt, the dilated right atrial wall eventually becomes less compliant and the incremental flow into this chamber results in accentuation of its " $v$ " wave relative to its "a" wave-that is, "left atrialisation" of the right atrial wave form. After many years, active contraction of the hypertrophied right atrium against the chronically overloaded, hypertrophied, and decreasingly compliant right ventricle results in a dominant "a" wave once more-that is, "normalisation" of the right atrial wave form-and a "sustained" presystolic right to left shunt is promoted while the left to right shunt may decrease. ${ }^{10}$ Since the left atrium remains relatively non-compliant, acting mainly as a conduit during venous filling, the right atrial " $a$ " wave kick is reflected in the left atrium-that is, "right atrialisation" of the left atrial wave form.

This explanation remains speculative, and other factors may well be implicated in the complex (and controversial) pressure-flow dynamics in atrial septal defect. The interesting studies reported in this issue emphasise the effects of age $\mathrm{e}^{1011}$ and the importance of phasic events ${ }^{11}$ and point to areas which require further investigation. Firstly, the presence of a right to left "a" wave gradient coincident with a right to left shunt in older patients needs to be proved. While these authors compare the height of the right atrial "a", "v", and mean pressures in groups with or without a right to left shunt, ${ }^{10}$ or with "left" or "right atrialisation" of the right or left atrial wave form respectively, 11 it is the phasic "a" or "v" wave gradient in each patient which dictates flow direction. (A study is now in progress in which flow direction at the atrial septal defect is observed by the recently developed external pulsed Doppler probe combined with cross sectional echocardiography and correlated with simultaneous left and right atrial pressures.)
Secondly, and more difficult to achieve, will be the demonstration of decreased compliance in the hypertrophied right ventricle before the development of appreciably raised end diastolic pressures and pulmonary hypertension. As yet there appears to be no satisfactory method for directly assessing chamber wall compliance other than that derived indirectly from pressure measurements.

In practical terms, the recognition of a "sustained" right to left shunt and " $a$ " wave gradient in the setting of normal or slightly raised pulmonary artery pressures, rather than a prominent right atrial " $v$ " wave as suggested by Parikh et al, ${ }^{11}$ should encourage early surgery even if the left to right shunt is not large,, 2731 since this situation implies increasing stiffness of the right atrium and ventricle and may be the harbinger of atrial arrhythmias or myocardial decompensation and tricuspid valve reflux.

\section{References}

1 Cournand A, Motley HL, Himmelstein A, Dresdale D, Baldwin J. Recording of blood pressure from the left auricle and pulmonary veins in human subjects with interauricular septal defect. Am f Physiol 1947; 150: 267-71.

2 Opdyke DF, Duomarco J, Dillon WH, Schreiber H, Little RC, Seely RD. Study of simultaneous right and left atrial pressure pulses under normal and experimentally altered conditions. Am $\mathcal{F}$ Physiol 1948; 154: 258-72.

3 Little RC, Opdyke DF, Hawley JG. Dynamics of experimental atrial septal defects. Am $\mathcal{F}$ Physiol 1949; 158: 241-50.

4 Brannon ES, Weens HS, Warren JV. Atrial septal defect. Study of hemodynamics by the technique of right heart catheterization. Am $\mathcal{J}$ Med Sci 1945; 210: 480-91.

5 Howarth S, McMichael J, Sharpey-Schafer EP. Cardiac catheterization in cases of patent interauricular septum, primary pulmonary hypertension, Fallot's tetralogy, and pulmonary stenosis. Br Heart f 1947; 9: 292-303.

6 Handelsman JC, Bing RJ, Campbell JA, Griswold HE. Physiological studies in congenital heart disease. V. The circulation in patients with isolated septal defects. Bulletin of the Fohns Hopkins Hospital 1948; 82: 615-32.

7 Hull E. The cause and effects of flow through defects of the atrial septum. Am Hean f 1949; 38: 350-60.

8 Hickam JB. Atrial septal defect. A study of intracardiac shunts, ventricular outputs, and pulmonary pressure gradient. Am Heart f 1949; 38: 801-12.

9 Selzer A, Lewis AE. The occurrence of chronic cyanosis in cases of atrial septal defect. Am $\mathcal{F}$ Med Sci 1949; 218: 516-24.

10 Galve E, Angel J, Evangelista A, Anivarro I, PermanyerMiralda G, Soler-Soler J. Bidirectional shunt in uncomplicated atrial septal defect. Br Heart $\mathcal{F} 1984$; 51: $480-4$.

11 Parikh DN, Fisher J, Moses JW, et al. Determinants and importance of atrial pressure morphology in atrial septal defect. Br Heart F 1984; 51: 473-9. 
12 Bard L, Curtillet J. Contribution à l'étude de la physiologie pathologique de la maladie bleue; forme tardive de cette affection. Revue de Médicine 1889; 9: 9931017.

13 Rasmussen K, Simonsen C, Storstein O. Quantitative aspects of right-to-left shunting in uncomplicated atrial septal defects. Br Hear $\mathcal{F}$ 1973; 35: 894-7.

14 Shaffer AB, Silber EN, Katz LN. Observations on the interatrial pressure gradients in man. Circulation 1954; 10: 527-35.

15 Swan HJC, Burchell HB, Wood EH. The presence of venoarterial shunts in patients with interatrial communications. Circulation 1954; 10: 705-13.

16 Dexter L. Atrial septal defect. Br Heart $\mathcal{F}$ 1956; 18: 209-25.

17 Levin AR, Spach MS, Boineau JP, Canent RV Jr, Capp MP, Jewett PH. Atrial pressure-flow dynamics in atria septal defects (secundum type). Circulation 1968; 37: 476-88.

18 Lind J, Wegelius C. Atrial septal defects in children: an angiocardiographic study. Circulation 1953; 7: 819-29.

19 Gamble WJ, Hugenholtz PG, Monroe RG, Polanyi M, Nadas AS. The use of fiberoptics in clinical cardiac catheterization. Circulation 1965; 31: 328-43.

20 Serruys PW, Van den Brand M, Hugenholtz PG, Roelandt J. Intracardiac right-to-left shunts demonstrated by two-dimensional echocardiography after peripheral vein injection. Br Heart $f$ 1979; 42: 429-37.

21 Kalmanson D, Veyrat C, Derai C, Savier CH, Berkman $M$, Chiche $P$. Non-invasive technique for diagnosing atrial septal defect and assessing shunt volume using directional Doppler ultrasound. Correlations with phasic flow velocity patterns of the shunt. Br Heart $\mathcal{F} 1972$; 34: 981-91.

22 Craig RJ, Selzer A. Natural history and prognosis of atrial septal defect. Circulation 1968; 37: 805-15.
23 Somerville W. Atrial septal defect: reversed shunt with normal pulmonary vascular resistance. $B r$ Heart $\mathcal{F} 1958$; 20: 265-6.

24 Gault JH, Morrow AG, Gay WA Jr, Ross J Jr. Atrial septal defect in patients over the age of forty years. Clinical and hemodynamic studies and the effects of operation. Circulation 1968; 37: 261-72.

25 Oakley CM, Braimbridge MV, Bentall HH, Cleland WP. Reversed interatrial shunt following complete relief of pulmonary valve stenosis. Br Heart $\mathcal{F}$ 1964; 26: 662-70.

26 Braunwald E, Fishman AP, Cournand A. Time relationship of dynamic events in the cardiac chambers, pulmonary artery and aorta in man. Circ Res 1956; 4: 100-7.

27 Maillis MS, Cheng TO, Meyer JF, Crawley IS, Lindsay $\mathrm{J} \mathrm{Jr}$. Cyanosis in patients with atrial septal defect due to systemic venous drainage into the left atrium. Am $\mathcal{F}$ Cardiol 1974; 33: 674-8.

28 Raghib G, Ruttenberg HD, Anderson RC, Amplatz K, Adams $\mathbf{P}$ Jr, Edwards JE. Termination of left superior vena cava in the left atrium, atrial septal defect, and absence of coronary sinus. Circulation 1965; 31: 906-18.

29 Haworth SG, Shinebourne EA, Miller GAH. Right-toleft interatrial shunting with normal right ventricular pressure. Br Heart $\mathcal{f}$ 1975; 37: 386-91.

30 Wood P. Congenital heart disease: atrial septal defect. $\mathrm{Br}$ Med Y 1950; ii: 693-8.

31 Ciafone RA, Aroesty JM, Weintraub RM, LaRaia PJ, Paulin S. Cyanosis in uncomplicated atrial septal defect with normal right cardiac and pulmonary arterial pressures. Chest 1978; 74: 596-9.

32 Suga H. Importance of atrial compliance in cardiac performance. Circ Res 1974; 35: 39-43.

33 Nakamura FF, Hauck AJ, Nadas AS. Atrial septal defect in infants. Pediatrics 1964; 34: 101-6.

34 Hunt CE, Lucas RV Jr. Symptomatic atrial septal defect in infancy. Circulation 1973; 47: 1042-8. 